\title{
Transcriptomic analysis of clam extra pallial fluids reveals immunity and cytoskeleton alterations in the first week of Brown Ring Disease development
}

\author{
Rahmani Alexandra 1, *, Corre Erwan 2, Richard Gaëlle 1, Bidault Adeline 1, Lambert Christophe 4, \\ Oliveira Louisi ${ }^{3}$, Thompson Cristiane ${ }^{3}$, Thompson Fabiano ${ }^{3}$, Pichereau Vianney ${ }^{1}$, Paillard Christine ${ }^{4,}{ }^{*}$
}

1 Univ Brest, CNRS, IRD, Ifremer, UMR 6539 LEMAR, F-29280, Plouzane, France

2 Sorbonne Universités, Université Pierre et Marie Curie-Paris 6, CNRS, FR2424, Station Biologique de

Roscoff, Roscoff, France

${ }^{3}$ Centro de Ciências da Saúde, Instituto de Biologia, Universidade Federal do Rio de Janeiro, Rio de Janeiro, Brazil

* Corresponding authors : Alexandra Rahmani, email address : alexandra.rahmani@univ-brest.fr ; Christine Paillard, email address : christine.paillard@univ-brest.fr

\begin{abstract}
:
The Brown Ring Disease is an infection caused by the bacterium Vibrio tapetis on the Manila clam Ruditapes philippinarum. The process of infection, in the extrapallial fluids (EPFs) of clams, involves alteration of immune functions, in particular on hemocytes which are the cells responsible of phagocytosis. Disorganization of the actin-cytoskeleton in infected clams is a part of what leads to this alteration. This study is the first transcriptomic approach based on collection of extrapallial fluids on living animals experimentally infected by V. tapetis. We performed differential gene expression analysis of EPFs in two experimental treatments (healthy-against infected-clams by V. tapetis), and showed the deregulation of 135 genes. In infected clams, a downregulation of transcripts implied in immune functions (lysosomal activity and complement- and lectin-dependent PRR pathways) was observed during infection. We also showed a deregulation of transcripts encoding proteins involved in the actin cytoskeleton organization such as an overexpression of $\beta 12$-Thymosin (which is an actin sequestration protein) or a downregulation of proteins that closely interact with capping proteins such as Coactosin, that counteract action of capping proteins, or Profilin. We validated these transcriptomic results by cellular physiological analyses that showed a decrease of the lysosome amounts and the disorganization of actin cytoskeleton in infected hemocytes.
\end{abstract}




\section{Graphical abstract}

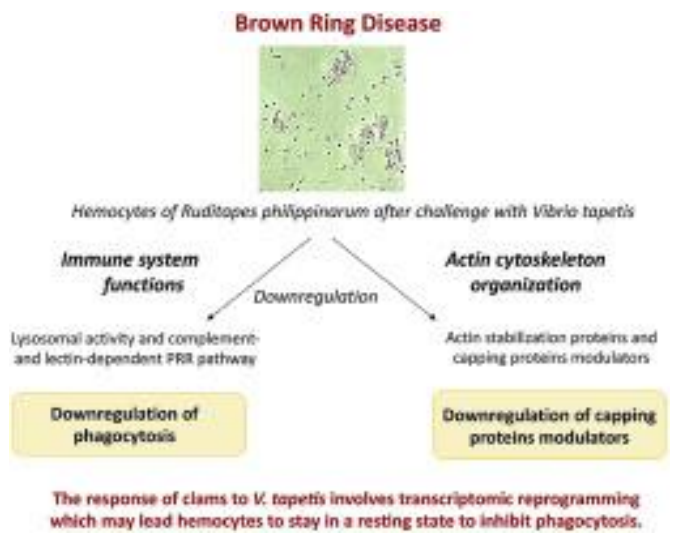

\section{Highlights}

- During BRD, most of regulated transcripts are involved in the immune system, translation and actin cytoskeleton organization. We showed a downregulation of the immune system related to the complement pathway through $\mathrm{C} 1 \mathrm{q}$ and lectin during infection. We highlighted a deregulation of transcripts involved in actin organization related to capping proteins. Physiological validations of immune and actin deregulation were performed. This study opens new perspectives to explore pathogenicity in the case of BRD.

Keywords : Brown Ring Disease, V. tapetis, R. philippinarum, Hemocytes, Actin cytoskeleton, bthymosin, Coactosin, Resting cells 


\section{Abbreviations}

37 ABP: Actin Binding Protein

38 BRD: Brown Ring Disease

39 EPF: Extrapallial Fluids

40 FSW: Filter Sterilized Seawater

41

42 


\section{INTRODUCTION}

Ruditapes philippinarum, the Manila clam, has been imported in Europe from Indopacific coasts in the early 70's. Ten years later, a disease causing a brown organic deposit at the inner face of the shell, between the pallial line and the edge of the shell, spread mostly all over Northern coasts of Europe, causing mass mortalities to this species [1,2]. This infection has been called the Brown Ring Disease (BRD, according to it macroscopic manifestations) and is due to the bacterium Vibrio tapetis $[3,4]$.

$V$. tapetis is a Gram-negative bacillus that acts, in most of cases, as an external microparasite, mainly in cold waters (optimal infection temperature of $14^{\circ} \mathrm{C}$ [5]) by spreading into the extrapallial fluids (EPF) of the Manila clam. Despite the fact that growth declines and shell deformations are frequently observed in this disease, tissue's infections are rare and only happen in case of pre-existing tissues lesions, then causing the death of animals. Nevertheless, BRD is a microparasitic infection which dynamics does not imply the death of animals $[4,6]$.

A particular symptom of BRD is the rounding of hemocytes in infected clams, thus revealing damages to the clam's immune system $[7,8]$. Indeed, hemocytes are key effectors of the immune defenses of the clam that eliminate pathogens by phagocytosis [9]. In a normal phagocytosis process, hemocytes spread their pseudopods which encapsulate and internalize bacteria and, by a phagosome/lysosome fusion, destroy the pathogen. During BRD infection, it was shown that $V$. tapetis causes a disorganization of the hemocyte actin cytoskeleton, resulting in the loss of hemocytes pseudopods (and thus, the rounding of cells) thus reducing its phagocytosis capacity [10]. V. tapetis is then able to multiply into hemocytes, finally resulting in cell membrane disruption. 
67 Bacteria can then spread into clams before being released by pseudo feces into the

68 environment (sediments) where they can infect other clams [7,11-13].

69 This study is the first transcriptomic approach based on collection of extrapallial fluids 70 (EPF) on living animals experimentally infected by $V$. tapetis. This study led to the

71 identification of a set of transcripts regulated during BRD infection, combined with 72 physiological experiments performed in order to check the validity of some of the major 73 interpretations raised from the differential expression analysis. This study gave new 74 insights to understand the pathogenicity of $V$. tapetis to Manila clams.

75

\section{MATERIALS AND METHODS}

\subsection{Clams in vivo infection, RNA extraction and sequencing}

Animals and experimental design are fully described in [14]. Two years-old clams were harvested in the Marennes-Oleron Bay (Charente Maritime, France) on May 5th, 2014. A first visual health diagnostic was performed on 50 clams in situ and no BRD clinical signs were observed. Clams were then transferred to Ifremer facilities in Plouzané (Finistère, France) and held in a 6-day quarantine with a chloramphenicol (8 $\left.\mathrm{mg}^{\mathrm{L}} \mathrm{L}^{-1}\right)$ treatment to avoid local contamination. After quarantine, animals were randomly divided and maintained in trays placed in eighteen 100 L-tanks equipped with air-lift systems (100 clams per tank). Water temperature was maintained at $13^{\circ} \mathrm{C}$ during the whole experiment so that infection by $V$. tapetis was favored [5]. Tanks were continuously supplied with filter sterilized seawater (FSW, filtered at $1 \mu \mathrm{m}$ and UV-sterilized) at a renewal rate of $50 \%$ per day and cleaned every two days. Clams were fed ad libitum with T-iso. Manila clams, $R$. philippinarum, were injected in the extrapallial cavity with $100 \mu \mathrm{L}$ of $V$. tapetis CECT4600 suspension at the concentration of $10^{7} \mathrm{CFU} . \mathrm{mL}^{-1}$ 
91 (Infected, 900 clams) or by Filter Sterilized Seawater (FSW, Control, 900 clams) as

92 described in Le Bris et al [15]. At 7 days post injection, EPFs of infected and control

93 clams were harvested and total RNAs were extracted with TRI reagent ${ }^{\circledR}$ according to

94 the procedure manufacturer (Sigma-Aldrich®). Presence or absence of the Brown Ring

95 Disease have been diagnosed according to the standardized methodology established

96 by Paillard et al [16] based on the presence and localization of brown deposit in clam

97 shells. We performed this diagnosis by an image analysis method using a $50-\mathrm{mm}$

98 CANON macroscopic lens and analyzed using Visilog 6.6 image analysis software, 99 according to image analysis methodology already performed [14,16]. This method 100 allows to visualize the shell and to analyze the presence of a brown deposit (BRD 101 positive diagnosis) with an image analysis software. BRD was diagnosed in all infected 102 clams whereas no BRD was found in control animals. As ribosomal RNA (rRNA) is the 103 most abundant component in total RNA, while not being informative in this kind of 104 RNAseq strategy, we performed two rRNA depletion steps, the first one targeting 105 bacterial rRNA and the second one targeting eukaryotic ones (by using the Ribo-Zero rRNA Removal Kits, bacteria and Human/Mouse/Rat, respectively, from Illumina). The

107 RNAs from seven clams, 3 healthy and 4 infected, were subjected to cDNA libraries 108 creation according to standard Illumina procedures (TruSeq Stranded mRNA Library 109 Prep Kit). All the libraries were sequenced, by Illumina Miseq PE300, at the Federal 110 University of Rio de Janeiro, Brazil. Other control and infected clams have been further 111 analyzed for other questions [14]. 
2.2. Transcriptomic analysis

116 Raw data analysis and differential expression evaluation were carried out using the 117 ABIMS Galaxy platform, Station Biologique de Roscoff, CNRS / Sorbonne Université, 118 France (http://galaxy.sb-roscoff.fr, January 2019).

119 Reads have been trimmed using AdaptorRemoval v2 [17], Trimmomatic v0.36.3 [18] and Prinseq v0.20.4 [19] in order to remove read adaptors, low quality sequences and 121 poly $(\mathrm{A})$ tails. Persistent rRNA were removed with SortMeRNA v2.1b.4 [20]. For the 122 differential analysis, all the reads were mapped to a dataset of 61747 transcripts (built 123 by Arnaud Tanguy, Station Biologique de Roscoff - CNRS, Sorbonne University, 124 France) obtained from a combination of $R$. philippinarum's stimulated hemocytes ESTs 125 (expressed sequences tag) library [21], from $R$. philippinarum's ESTs deposited in NCBI 126 EST database (https://www.ncbi.nlm.nih.gov/nucest/) and sequences deposited in the 127 Ruphibase database (http://compgen.bio.unipd.it/ruphibase/)). Transcripts abundances were estimated by using the "Align and Build expression matrix" pipeline (mapping with 129 bowtie + reads estimation with RSEM) of the Trinity suite v2.4.0.2 [22]. The statistical 130 analysis of differentially expressed transcripts were done using the "Differential 131 expression analysis" pipeline of Trinity suite v2.4.0 (using DESeq2) and "Extract and 132 cluster differentially expressed transcripts" pipeline of Trinity suite v2.4.0 [22]. We have 133 set up parameters to exclude differential expression with a LogFoldChange between -2 134 and 2. Transcripts were considered as significantly differentially expressed if the p-value 135 adjusted by FDR (false discovery rate) is $<10^{-3}$. The identified deregulated transcripts 136 were subjected to blast2GO for re-annotation, including blastX vs the $\mathrm{NCBI} n$, refseq 137 and swissprot (2018 version) non redundant databases, interpro, GO mapping and GO 138 annotation, all with standard parameters. All the annotations and functions were 
139 carefully manually checked. The sequencing data have been made available at the

140 European Nucleotide Archive (project PRJEB23385). The analysis data are given in 141 Table S1.

\subsection{Clams in vitro infection : bacterial exposure}

Animals used in this study were Manila clams from the SATMAR shellfish aquaculture site in Marennes (Charente-Maritime, France). The clam pool was acclimatized in oxygenated seawater using a bubbler at $14^{\circ} \mathrm{C}$. Hemolymph was harvested directly from

147 the adductor muscle. Each hemolymph was sampled individually and the quality of the

148 hemocytes present in this fluid was checked by observation under the microscope

149 (presence of pseudopods, few round-shaped hemocytes). Good quality hemolymph 150 samples were pooled and the hemocytes enumerated by using a Malassez cell. For 151 exposure assays, hemolymph was exposed to a bacterial suspension (in FSSW) of $V$. 152 tapetis CECT4600, at a 25/1 : bacteria/hemocyte ratio. Hemocytes exposure were 153 performed in at least 3 replicates and two independent experiments for each condition 154 tested. Briefly, $100 \mu \mathrm{L}$ of hemolymph was added in 24 -well plates. After a few minutes, 155 in order to let hemocytes attach on the bottom of the plate, $100 \mu \mathrm{L}$ of bacterial 156 suspension was added for the exposed samples, and $100 \mu \mathrm{L}$ of FSSW for the controls.

159 To visualize F-actin in control and infected hemocytes, we used the fluorescent probe 160 Rhodamine Phalloidin (Invitrogen). Exposure assays were performed as described 161 above. After 3 hours of challenge, we collected the supernatant and added $30 \mu \mathrm{L}$ of 162 Triton $\mathrm{X}-1000.1 \%$ for 15 minutes. Triton permeabilizes cells, thus allowing probes to 
163 enter the cell. $2 \mu \mathrm{L}$ of Rhodamine-phalloidin (Stock solution dissolved in $1.5 \mathrm{~mL}$ 164 methanol) was then added to each sample (hemolymph non exposed and exposed to $V$.

165

166

167

168

169

170

171

172

173

174

175

176

177

178

179

180

181 182 (Invitrogen, emission from 550 to $700 \mathrm{~nm}$, final concentration $1 \mu \mathrm{M}$ ) to each well. The 24 183 wells plates were then let 2 hours more, in dark conditions at $18^{\circ} \mathrm{C}$, to reach the 3 hours 184 185 tapetis) which were stained for 20 min, on ice, without light. Epifluorescence microscopy was then performed by using a ZEISS AXIO observer Z1 inverted microscope with a wavelength of excitation BP (band pass) 550/25 nm, Beam splitter $570 \mathrm{~nm}$ and of emission BP 605/70 nm. Cells were observed both in red epifluorescence and in bright field.

\subsubsection{Lysotracker assay}

The LysoTracker ${ }^{\circledR}$ probes (Molecular Probes ${ }^{\circledR}$ ) are fluorescent acidotropic probes for labeling and tracking acidic organelles in live cells, according to the manufacturer definition. We have developed and tested a method to characterize the amount of acidic organelles on hemocytes exposed to $V$. tapetis or FSSW for control. Lysotracker assay is performed during the in vitro bacterial exposure assay based on the rounding of hemocytes caused by $V$. tapetis previously developed by Choquet et al. [7]. Our protocol allows to perform both tests on the same sample, and then to correlate the rounding phenotype to the cell content in acidic organelles.

Hemocytes exposure were performed as described above. The 24 wells plates were incubated 1 hour at $18^{\circ} \mathrm{C}$ before addition of $4 \mu \mathrm{L}$ of $50 \mu \mathrm{M}$ Lysotracker ${ }^{\circledR}$ Red DND-99 exposition. The contents of the wells were then transferred in 5-mL cytometry polystyrene tubes (Falcon®, BD Biosciences, San Jose, CA, USA). 
186 First, flow cytometry analyses were performed by using a BD FACSVerse flow cytometer

187

188

189

190

191

192

193

194

195

196

197

198

199

200

201

202

203

204

205

206

207

208

209 using its blue laser (488 $\mathrm{nm}$ ) as an excitation source. The mean red fluorescence level (Lysotracker fluorescence linked to acidic organelles) of the selected hemocytes was measured using the PerCP-Cy5.5 detector of the flow cytometer (700/54 nm).

Second, $2 \mu \mathrm{L}$ of a $100 \mathrm{X}$ dilution in ultra pure water of a commercial solution of SYBRGreen® I nucleic acid gel stain 10 000X in DMSO (Life Technology, USA) were added in each cytometry tube for $10 \mathrm{~min}$, at room temperature, in dark condition, before a second flow cytometry analysis. Hemocytes were selected according to their green fluorescence (SYBR-Green, FITC detector of the flow cytometer 527/32 nm). Addition of SYBR-Green also allowed to quantify the number of non-adherent hemocytes in our sample.

This second flow cytometry analyses of red fluorescence were performed using a red laser $(640 \mathrm{~nm})$ as an excitation source and fluorescence was measured using the APC detector of the flow cytometer $(660 / 10 \mathrm{~nm})$. This detector was selected instead of the PerCP-Cy5.5 detector (700/54 nm) to overcome a possible SYBR-Green fluorescence overlapping. Results are expressed in mean red fluorescence level per hemocyte in arbitrary units (UA).

\section{RESULTS AND DISCUSSION}

3.1. Transcriptomic results: differential expression analysis

The total number of reads was 29.3 million, with an average length of $262.5 \mathrm{bp}$, for a total coverage of $5.62 X$. Differential expression analysis revealed 135 differentially expressed genes, which 90 and 45 appeared down- and up- regulated, respectively, in the EPF treatment ( $V$. tapetis infected clams), as compared to the control treatment. We 
210 could obtain an annotation, and functional information, for 118 of them, which were

211 classified according to their probable cellular role (Table S1, Table 1). In all, $85 \%$ of

212 these transcripts belonged to four functional categories, ie. translation (34 transcripts),

213 cytoskeleton (27), immune response (24) and metabolism (15) (Table 1). The

214 deregulation of these transcripts in clams EPFs appears clearly related to the infection

215 by $V$. tapetis. In the following section, we discuss the pathogen induced modulation of

216 the immune response, which is a major point to better understand the host-pathogen

217 interactions. Table 2 summarizes all the differentially expressed transcripts involved in

218 cytoskeleton or immunity. It is noteworthy that the whole reads were also mapped

219 against the recently released genome of $V$. tapetis CECT 4600 [23], but no significant

220 correspondence has been found with the pathogen. 
233

234

235

\begin{tabular}{llll}
\hline \hline FUNCTIONS & $\begin{array}{l}\text { Total number of } \\
\text { transcripts }\end{array}$ & $\begin{array}{l}\text { DOWN REGULATED IN } \\
\text { INFECTED CLAMS }\end{array}$ & $\begin{array}{l}\text { UP REGULATED IN } \\
\text { INFECTED CLAMS }\end{array}$ \\
\hline \hline Translation & 34 & 23 & 11 \\
Cytoskeleton & 27 & 18 & 9 \\
Immunity & 24 & 18 & 6 \\
Metabolism & 15 & 9 & 6 \\
Proteins processing & 6 & 4 & 2 \\
Unknown / Hypothetical / Other & 29 & 18 & 11 \\
\hline
\end{tabular}

Table 1: Number and functions of the transcripts differentially expressed in clams EPFs during V. tapetis infection

236

237 
Table 2: Transcripts significantly regulated during infection by $V$. tapetis and implied in the clam immune system or in actin cytoskeleton organization. FDR : false discovery rate, LogFC : Log Fold-Change.

\begin{tabular}{|c|c|c|c|c|c|}
\hline DOWN REGULATED IN INFECTED CLAMS & & & UP REGULATED IN INFECTED CLAMS & & \\
\hline Seq. Description & $\log \mathrm{FC}$ & FDR & Seq. Description & $\log \mathrm{FC}$ & FDR \\
\hline Immune system & & & Immune system & & \\
\hline cathepsin K-like & -10.52 & $1.25 \mathrm{E}-05$ & complement C1q-like protein 4 & 11.02 & 4.29E-04 \\
\hline cathepsin $\mathrm{K}$ & -10.04 & 4.87E-04 & cyclophilin-like protein & 9.45 & 3.93E-04 \\
\hline cathepsin I & -9.93 & 4.16E-04 & lysozyme & 9.16 & 4.87E-04 \\
\hline cathepsin L1 & -9.81 & 3.31E-04 & Cyclophilin A & 7.60 & $8.56 \mathrm{E}-05$ \\
\hline cathepsin I & -9.77 & $2.27 \mathrm{E}-11$ & Dermatopontin & 6.29 & $8.88 \mathrm{E}-04$ \\
\hline saposin b domain-containing protein & -9.42 & $1.79 \mathrm{E}-11$ & cyclophilin-like protein & 4.91 & $9.48 \mathrm{E}-04$ \\
\hline saposin B domain-containing protein precursor & -8.74 & 2.95E-09 & & & \\
\hline cell death-inducing $\mathrm{p} 53$-target protein 1 & -8.46 & $2.95 \mathrm{E}-09$ & & & \\
\hline cathepsin S & -8.22 & $2.50 \mathrm{E}-05$ & & & \\
\hline ferric-chelate reductase 1 & -8.08 & 4.99E-04 & & & \\
\hline CD63 antigen & -7.51 & $1.44 \mathrm{E}-04$ & & & \\
\hline defense protein 3-like & -7.30 & $5.66 \mathrm{E}-04$ & & & \\
\hline complement C1q-like protein 4 & -7.24 & 4.50E-05 & & & \\
\hline galectin-3 isoform 1 & -7.20 & $6.22 \mathrm{E}-04$ & & & \\
\hline c1q domain containing protein $1 q 13$ & -6.89 & $1.83 \mathrm{E}-06$ & & & \\
\hline complement c1q TNF-related protein 3-like isoform 2 & -6.34 & $3.82 \mathrm{E}-07$ & & & \\
\hline complement c1q-like protein 2 precursor & -5.76 & 2.63E-04 & & & \\
\hline saposin b domain-containing protein & -5.04 & $1.25 \mathrm{E}-05$ & & & \\
\hline Actin cytoskeleton organization & & & Actin cytoskeleton organization & & \\
\hline actin & -11.30 & $1.49 \mathrm{E}-04$ & actin & 12.46 & $7.50 \mathrm{E}-05$ \\
\hline actin & -11.21 & $8.94 \mathrm{E}-05$ & cytoplasmic actin & 10.82 & $1.46 \mathrm{E}-04$ \\
\hline actin & -10.49 & $5.02 \mathrm{E}-05$ & actin & 10.82 & $1.49 \mathrm{E}-04$ \\
\hline cytoplasmic actin & -10.18 & $4.81 \mathrm{E}-08$ & Kinesin & 10.33 & $4.34 \mathrm{E}-08$ \\
\hline Myophilin & -10.12 & $1.98 \mathrm{E}-05$ & actin & 8.84 & $9.99 \mathrm{E}-04$ \\
\hline cytoplasmic actin & -10.09 & $5.50 \mathrm{E}-05$ & thymosin beta- 12 & 8.76 & 4.93E-04 \\
\hline coactosin-like protein & -9.73 & 2.07E-05 & actin & 8.57 & $6.14 \mathrm{E}-04$ \\
\hline beta-actin & -8.86 & $1.27 \mathrm{E}-04$ & cytoplasmic actin & 8.34 & $6.65 \mathrm{E}-04$ \\
\hline cytoplasmic actin & -8.30 & 2.95E-09 & myosin light chain & 5.57 & $1.98 \mathrm{E}-05$ \\
\hline $\operatorname{actin} 5 c$ & -7.96 & $4.99 E-04$ & & & \\
\hline cytoplasmic actin & -7.45 & $4.99 \mathrm{E}-04$ & & & \\
\hline cytoplasmic actin & -7.37 & $7.39 \mathrm{E}-04$ & & & \\
\hline coactosin-like protein & -6.94 & 4.93E-04 & & & \\
\hline cytoplasmic actin & -6.84 & $2.82 \mathrm{E}-07$ & & & \\
\hline cysteine and glycine-rich protein 3 & -6.80 & $5.97 \mathrm{E}-04$ & & & \\
\hline profilin & -6.63 & $9.08 \mathrm{E}-04$ & & & \\
\hline cysteine and glycine-rich protein 3 & -6.63 & $8.28 \mathrm{E}-04$ & & & \\
\hline dynein light chain, cytoplasmic & -6.52 & $9.99 \mathrm{E}-04$ & & & \\
\hline
\end{tabular}


248 Extrapallial fluids (EPFs) play an essential role in the biomineralization of the shell of 249 bivalves. Given the particular etiology and symptoms of BRD, this compartment, 250 containing numerous hemocytes [24], is particularly interesting to better understand both 251 the infection process and how the clam's hemocytes fight against it. For this reason, in 252 this study, V. tapetis infection was carried out directly inside the EPFs passing through 253 the periostracal lamina barrier to accelerate the immune response, particularly in EPFs.

254 A transcript encoding lysozyme was found to be upregulated in response to $V$. tapetis 255 infection. In previous studies, lysozyme activities in cell lysates of extrapallial fluids were 256 significantly higher 7 days after $V$. tapetis inoculation into the pallial cavity, as compared 257 to control ones [24]. The antibacterial protein lysozyme, which is circulating in body 258 fluids such as hemolymph and EPFs, is an important line of defense of the animal 259 against bacterial pathogens because of their bacteriolytic properties $[5,25]$.

261 Only five transcripts directly related to immunity were actually upregulated during $\mathrm{V}$. 262 tapetis infection. Beside the lysozyme, three genes belonging to the cyclophilin family, 263 as well as dermatopontin, were upregulated (Table 2). Dermatopontin is a tyrosine-rich 264 acidic matrix protein (TRAMP) that primarily acts as a structural component of the 265 extracellular matrix. However, this protein was shown to modulate TGF- $\beta$ activity as well 266 as cell-cell aggregation during infection in invertebrates [26]. Dermatopontin was 267 previously shown to be upregulated in the EPFs and hemolymph of clams during BRD 268 [27]. Not less than 3 cyclophilin transcripts appeared upregulated following $V$. tapetis 269 infection. Cyclophilin was shown to be transcriptionally upregulated during infection in 
270 the shrimp [28]. In the clam $R$. philippinarum, Chen et al. [29] previously showed that

271 two cyclophilin genes were differentially expressed in hemolymph when exposed to 272 pathogenic bacteria.

274 The cellular component of the innate immune system also includes more specific 275 pathways that involve the recognition of specific Pathogen-Associated Molecular 276 Patterns (PAMPs) by pattern recognition receptor (PRRs). Most of these receptors are 277 membrane proteins (eg. Toll like receptors), but they also include soluble proteins (eg. 278 SAP, CRP) that are activated by the C1q proteins of the complement system [30-32]. 279 When the pathogen is recognized by either C1q proteins or Mannose Binding Proteins 280 (MBP), these proteins activate the complement pathway through the "classical pathway" 281 or the "lectin pathway" resulting in phagocytosis with the formation of a phagosome. 282 [30]. Pathogens are then degraded after the fusion of the phagosome and the lysosome 283 by the action of low $\mathrm{pH}$, acid hydrolases and by reactive oxygen species produced during the pathogen-induced oxidative burst [33].

In this study, 18 out of the 24 deregulated genes potentially involved in clams' immune defenses were downregulated. Nine of these transcripts encoded proteins clearly related to lysosome activity (ie., cathepsins, saposins), four were C1q complement proteins, 289 while others encoded CD63 (a cell death-inducing P53-target protein), galectin 3, as well 290 as two proteins annotated as Defense Proteins, that should be related to ferric iron 291 chelation/reduction. Different transcripts of C1q proteins were also reported in the clam 292 R. decussatus infected with Perkinsus olseni [34], and in R. philippinarum infected with 293 V. tapetis [27]. 
295 Pathogens have developed many strategies to bypass the immune defenses of their hosts. In the particular case of BRD, it has been shown that the immune system of

297 clams is not able to eliminate $V$. tapetis during infection, even if very high phagocytic

298 rates of $V$. tapetis were measured when the pathogen is injected into the extrapallial 299 space [35]. However, during phagocytosis by hemocytes, V. tapetis could persist and 300 multiply within hemocytes and was also able to inhibit the phagosome-lysosome fusion, 301 thus preventing its destruction [6]. The repression of nine genes encoding saposins (2) 302 and cathepsins (7) could reflect the ability of the bacteria to inactivate the lysosomal 303 functioning. Indeed, Cathepsins K, L, L1 and S are cysteine proteases [36][37] that 304 belong to lysosomal acid hydrolases, that are normally released during the phagosome305 lysosome fusion. Saposins are small lysosomal proteins that participate 306 (stimulate/activate) to the hydrolysis of sphingolipids and many other lipids [38]. 307 Interestingly, the CD63 antigen belongs to the family of lysosomal associated proteins 308 (LAMPs) and is also considered as an indicator of the phagosome-lysosome fusion [39].

309 In all, these results strongly suggest that lysosomal function plays a key role in the 310 development of BRD.

311 In addition to the predominant role of lysosome inactivation, the repression of genes 312 encoding three complement $\mathrm{C} 1 \mathrm{q} /$ tumor necrosis factor proteins, and of the galectin 3 , 313 might suggest an important role for the complement- and lectin-dependent PRR 314 pathways $[40,41]$. The downregulation of a cell death-inducing P53-target protein, which 315 is known to regulate the TNF-alpha-mediated apoptosis, might also suggest a role for 316 apoptotic processes during the infectious process [42]. 
317 Finally, the downregulation of a protein annotated as 'defense protein', that contains a

318 ferric-chelate reductase domain, could reflect an important role for iron acquisition

319 during the infectious process. Interestingly, the concomitant downregulation of ferritin,

320 which is implied in iron storage [43] and reduction of reactive oxygen species (ROS)

321 accumulation [44], could also be related to this, allowing then more availability of iron for

322 the pathogen.

3.3. Ribosomal proteins

325 We also identified deregulated genes involved in functions other than immunity, but 326 whose deregulation could strongly influence the host's immune response. This is 327 especially the case for cytoskeleton reorganization, thoroughly discussed thereafter, but 328 also for translation proteins, which is the most modified category and, in other ways, for 329 genes encoding proteins which function was categorized in metabolism and protein 330 processes (Table 1).

331 A major reorganization of the translational apparatus may have occurred in response to 332 V. tapetis infection as a result of gene expression reprograming (32 ribosomal proteins 333 and 2 translation elongation factors). Eleven genes were induced, while 23 genes had 334 their expression reduced (Table 1). Ribosome inactivation resemble one of the major 335 symptoms of the so-called 'metabolic depression' observed in many environmental 336 stress responses in several marine mollusks $[45,46]$. However, it is noteworthy that the 337 expression of several ribosomal proteins was increased during infection (S14, S21, S30, 338 L21, SA, P0), and others appeared both repressed and induced (L3, L8, L27). For these 339 last proteins, we presume that the protein exists as different alternate isoforms (with 340 different regulations). 
341 It is noteworthy that ribosomal proteins are increasingly studied for their alternate roles, ie. independent of their ribosomal function [45]. More specifically, it should be noted that

343 the role of ribosomal proteins in the regulation of the innate immune response has been 344 well documented in recent years [45], especially the major role of the ribosomal protein $345 \mathrm{~L} 13 \mathrm{~A}$ in the GAIT complex, that selectively modulates the translation of some genes 346 involved in the interferon- $\gamma$-mediated inflammatory response [47]. However, many other 347 examples have been reported. For example, the ribosomal proteins S14 and L8, both 348 found upregulated in our study, would be able to activate P53 and the major regulator $349 \mathrm{NF}-\kappa \mathrm{B}$, respectively $[48,49]$. It would be particularly interesting to perform new focused 350 investigations to better understand the role of the translation apparatus in the 351 development of the BRD.

\subsection{Actin cytoskeleton organization}

Actin filaments (F-actin) belong to the cell cytoskeleton and are dynamically polymerized 356 and depolymerized from monomers of actin (G-actin) into the cell to enable cellular 357 activities such as locomotion, exocytosis or phagocytosis. The actin cytoskeleton is also 358 responsible for the cell shape. In this study, we showed that at least 27 transcripts 359 involved in actin cytoskeleton organization were differentially expressed during infection, 360 among which 9 were induced while 18 had their expression reduced. Genes 361 downregulated during infection are mainly involved in actin filament stabilization such as 362 myophilin, a member of calponin protein family [50,51], cysteine glycine rich protein 363 (CSRP) 1 [52,53] and dynein light chain [54]. Furthermore, our results showed that 
expression regulation during infection also affected transcripts involved in cell motility such as up regulation of the Myosin light chain, which role in hemocytes phagocytosis in shrimp was already described [55].

Two transcripts downregulated during BRD might give additional information on the molecular mechanisms related to infection. The first one encodes a Coactosin like protein that counteracts the action of capping proteins that reduce or slow down actin polymerization [56]. The second one encodes Profilin, an 'actin binding protein' (ABP) which is known to interact with others ABPs such as $\beta 4$-thymosin [57]. The role of profilin in actin polymerization is quite complex. In the presence of molecules that stimulate actin assembly, profilin displaces $\beta 4$-thymosin, bounds to G-actin and promotes actin polymerization [58]. Furthermore, profilin regulates the effects of capping proteins. Hopmann and Miller [59] demonstrated that balanced activities of capping protein and profilin are essential in the regulation of actin dynamics and organization in Drosophila.

Capping proteins can be associated, in resting cells, with actin filament by electrostatic interactions on the barbed $(+)$ end. By changing the conformation of the capping protein during this interaction, the + end is no longer available for G-actin and polymerization is then inhibited $[60,61]$.

In this study, we also highlighted an overexpression of $\beta 12$ thymosin transcripts during infection by $V$. tapetis. $\beta 12$-thymosin belongs to the ABPs family. Fifteen variants of $\beta$ thymosin proteins have been described in many vertebrates and invertebrates, but not 
on prokaryotes and yeasts. They are able to bind ATP-G-actin complex (1:1), the monomeric form of actin, and stabilized it. This actin-monomer sequestration prevents them from polymerization by changes in actin conformation $[60,62]$. Many factors are actually involved in the dynamics of actin in eukaryotic cells, such as e.g. the ATP concentration or the Critical Concentration (Cc) of G-actin monomers.

\subsection{Physiological verification of differential expression analysis}

Transcriptomics analysis is a very powerful tool to give, in a single experiment, a broad overview of the multiple processes potentially involved in a biological response. In our study, we showed the deregulation of many transcripts encoding proteins involved in immunity and in the dynamics of actin cytoskeleton, thus suggesting an important role for these biological processes during infection of $R$. philippinarum by $V$. tapetis. Therefore, we performed additional experiments in order to check the validity of some of the major interpretations raised from the differential expression analysis.

First, RNA-seq data showed a downregulation of many transcripts encoding proteins involved in the lysosomal activity, thus suggesting a crucial of related biological process during infection. We thus aimed at checking the actual effect of $V$. tapetis exposure on the lysosomal activity of $R$. philippinarum hemocytes, by using the Lysotracker assay, which is commonly recognized as an efficient proxy of the amount and activity of acidic organelles within eukaryotic cells.

As previously described $[7,8]$, we first confirmed that the exposition to $V$. tapetis CECT4600 induces a loss of hemocytes adherence as compared to the control (Fig. 1), and results in a rounded phenotype. In these experimental conditions, we observed that 
411 the loss of adherence is accompanied by a two-fold decrease of acidic organelles in

412 hemocytes exposed to $V$. tapetis CECT4600 as compared to the control (Fig. 2). As a 413 consequence, we hypothesize that the general depletion of lysosomal transcripts 414 observed in the RNAseq experiment should result from the decreased number of 415 lysosomes in EPFs-derived hemocyte cells.

417 Second, as many transcripts involved in actin-cytoskeleton dynamics were deregulated, 418 we aimed at observing the F-actin filaments in hemolymph that had been exposed or not 419 to $V$. tapetis (Fig. 3), by performing a phalloidin staining experiment. Results presented 420 in the Fig. 3 clearly show the loss of pseudopods and rounding of hemocytes after $V$. 421 tapetis exposure (Fig. 3C and 3D). In these conditions, it is noteworthy that the F-actin 422 filaments were clearly mainly located at the periphery of cells in healthy hemocytes (Fig. 423 3B), while phalloidin staining revealed a diffuse localization of F-actin in cells exposed to $424 V$. tapetis (Fig. 3D). These results are consistent with previous works showing F-actin 425 network disorganization in diseased hemocytes in another clam species, Mya arenaria 426 [63], as well as with the infection model developed by Paillard [6] considering that $V$. 427 tapetis induces a loss of phagosome-lysosome formation during infection of the Manila 428 clam R. philippinarum.

3.6. Hypothetical model of clam-Vibrio tapetis interaction

431 We took advantage of our data to propose an hypothetical model that encompasses 432 bacterium recognition (through microbe-associated molecular pattern [MAMP]) and 433 some relevant metabolic processes overrepresented in the transcriptomic profile of 434 clams EPFs in response to $V$. tapetis. Altogether, these results are consistent with the 
435 knowledge we have about the influence of the BRD on actin cytoskeleton [13]. Indeed,

436 in the case of $R$. philippinarum's infection by $V$. tapetis, the bacterium is phagocyted into

437 clam's hemocytes which leads to hemocytes actin-cytoskeleton disorganization. The

438 result of this perturbation is the loss of pseudopods (ie. rounding phenotype) and then

439 the loss of hemocytes adhesion properties. This consequence of $V$. tapetis infection on

440 clams is commonly used to measure strains virulence by in vitro characterization [7].

441 The fact that transcripts such as coactosin or profilin, that interact with either capping 442 proteins and/or ABPs, are downregulated during infection, let us to formulate different 443 hypothesis. Considering our results and the knowledge on actin dynamics, we made the 444 hypothesis that infection might trigger a deregulation of capping protein which would 445 lead hemocytes to be blocked in a "resting cell state". According to our model, capping 446 proteins would block the + end polymerization in infected hemocytes, then increasing 447 the levels of free G-actin [60]. In this case, Mannherz and Hannappel [60] described that 448 in case of resting cells, $\beta$-thymosins massively bound to free $\mathrm{G}$-actin, thus decreasing its 449 concentrations, thus stalling net polymerization [60]. On the other hand, they also report 450 that during this process, profilin concentration is low and most of it is inactivated. This 451 hypothesis would need additional experiments but might explain the disorganization of 452 the F-actin network observed during infection that gives to hemocytes this 'rounded' 453 phenotype after challenge with $V$. tapetis.

455 Figure $4 \mathrm{~A}$ to $4 \mathrm{C}$ represent the conceptual model of the Manila clam EPF infection by $V$. 456 tapetis in order to understand functions and interactions between the proteins that were 457 deregulated in our experiments, and their place in the immune response to infection and 
458 actin dynamics polymerization process. Figure 4A represents the immune response of

459 healthy hemocytes to foreign bacteria. Foreign bacteria are opsonized and phagocytized

460 by hemocyte. After fusion between the phagosome and the lysosome, bacteria are

461 destroyed. Figure 4B represents early stage of hemocytes infection by $V$. tapetis and

462 thus downregulation of transcripts related to pathogen recognition ( $\mathrm{C} 1 \mathrm{q}$ proteins and

463 lectin) or to decrease of lysosomal activity as demonstrated in this study. Figure 4C

464 represents the deregulation of the immune system in hemocytes infected by $V$. tapetis

465 inducing a rounding phenotype related to infection with absence of pseudopods

466 formation.

467

468

4. CONCLUSION

469 This study presents the first transcriptomic approach on EPFs of experimentally infected

470 clams. It brought novel insights on the interaction between $V$. tapetis and clam by

471 exploring in vivo gene expression during the infection. This study revealed a

472 downregulation of the immune response, especially the complement pathway and

473 Iysosomal activity, the disorganization of the actin cytoskeleton, accompanied by

474 ribosomal genes deregulation. 
FUNDINGS

477 This project received grants from the H2020 European project "VIVALDI" (grant 478 agreement N678589), CNRS INSU EC2CO-MicrobiEn "MICROPAL", CAPES479 COFECUB (MICROBIV) and PVE Brésil. This work was also supported by the University 480 of Western Brittany (UBO), and the "investment for the future" programs LabexMER 481 (ANR-10-LABX-19) and ISblue (ANR-17-EURE-0015).

482

483

484

485

486

487

488

489

490

491

492

493

494

495

496

497

498

499

\section{ACKNOWLEDGMENTS}

We warmly thank Fabien Fonteneau (EARL Les Claires de Bonsonge, Marennes, France) for providing the clams. We thank colleagues from the Federal University of Rio De Janeiro, Brazil who welcomed us in Rio. Wethank N. Le Goïc, F. Nunez, H. Hégaret, C. Fabioux, I. Paul-Pont, F. Le Grand, F. Riera, AL. Cassone, P. Le Souchu, A. Muir, E. Harney, Y. Epelboin, M. Fuhrmann, M. Provost, L. Frère, F. Boullot, B. Dubief, M. Czamanski, R. Morvezen, V. Foulon, M. Protat, C. Quéré, and A. Huvet for their help for animals conditioning, injections and samplings.

\section{AUTHOR CONTRIBUTIONS}

$\mathrm{CP}, \mathrm{FT}$ and VP acquired funds and coordinated the study. GR, AB and CP designed and performed the experimental infection. $A B$ performed RNA extractions and libraries preparations, with the advices of LO. LO and FT performed DNA sequencing. AR and EC performed bioinformatics analysis, with inputs from VP. AR and CL performed the flow cytometry analyses. AR, VP and CP wrote the article (the original draft was written by $A R)$. The article was carefully reviewed by other co-authors, who all approved the final version. 
500

501

502

503

504

505

506

507

508

509

510

511

512

513

514

515

516

517

518

519

520

521

522

523

524

525

526

527

528

529

530

531

532

533

534

535

536

537

\section{REFERENCES}

[1] C. Paillard, Etiologie et caractérisation de la maladie de l'anneau brun chez la palourde d'élevage Ruditapes philippinarum, 1992.

[2] C. Paillard, L. Percelay, M. Le Pennec, D. Le Picard, Origine pathogène de l'«anneau brun» chez Tapes philippinarum (Mollusque, bivalve), Comptes Rendus de l'Académie Des Sciences. Série 3, Sciences de La Vie. 309 (1989) 235-241.

[3] P. Maes, C. Paillard, Effect du Vibrio P1, pathogene de Ruditapes philippinarum, sur d'autres espèces de bivalves, in: Les Mollusques Marins: Biologie et Aquaculture, Brest (France), 9 Nov 1990, 1992.

[4] J.J. Borrego, D. Castro, A. Luque, C. Paillard, P. Maes, M.T. Garcia, A. Ventosa, Vibrio tapetis sp. nov., the causative agent of the brown ring disease affecting cultured clams, International Journal of Systematic and Evolutionary Microbiology. 46 (1996) 480-484.

[5] Paillard, B. Allam, R. Oubella, Effect of temperature on defense parameters in Manila clam Ruditapes philippinarum challenged with Vibrio tapetis, Diseases of Aquatic Organisms. 59 (2004) 249-262.

[6] Paillard, Rôle de l'environnement dans les interactions hôtes-pathogènes; développement d'un modèle de vibriose chez les bivalves, Habilitation à Diriger Des Recherches (HDR), Université de Bretagne Occidentale, Brest. (2004).

[7] G. Choquet, P. Soudant, C. Lambert, J.-L. Nicolas, C. Paillard, Reduction of adhesion properties of Ruditapes philippinarum hemocytes exposed to Vibrio tapetis, Diseases of Aquatic Organisms. 57 (2003) 109-116.

[8] F. Jeffroy, C. Paillard, Involvement of nitric oxide in the in vitro interaction between Manila clam, Ruditapes philippinarum, hemocytes and the bacterium Vibrio tapetis, Fish \& Shellfish Immunology. 31 (2011) 1137-1141. doi:10.1016/j.fsi.2011.10.008.

[9] A.F. Rowley, A. Powell, Invertebrate Immune Systems-Specific, Quasi-Specific, or Nonspecific?, The Journal of Immunology. 179 (2007) 7209-7214. doi:10.4049/jimmunol.179.11.7209.

[10] B. Allam, S.E. Ford, Effects of the pathogenic Vibrio tapetis on defence factors of susceptible and non-susceptible bivalve species: I. Haemocyte changes following in vitro challenge, Fish \& Shellfish Immunology. 20 (2006) 374-383. doi:10.1016/j.fsi.2005.05.012.

[11] C. Paillard, An ecological approach to understanding host-pathogen-environment interactions: the case of Brown Ring Disease in clams, 2016. https://hal.archivesouvertes.fr/hal-01426301 (accessed February 22, 2017).

[12] E. Lane, T.H. Birkbeck, Species specificity of some bacterial pathogens of bivalve molluscs is correlated with their interaction with bivalve haemocytes, Journal of Fish Diseases. 23 (2000) 275-279.

[13] F. Brulle, F. Jeffroy, S. Madec, J.-L. Nicolas, C. Paillard, Transcriptomic analysis of 
Ruditapes philippinarum hemocytes reveals cytoskeleton disruption after in vitro Vibrio tapetis challenge, Developmental \& Comparative Immunology. 38 (2012) 368-376. doi:10.1016/j.dci.2012.03.003.

[14] G. Richard, Approche mécanistique de la réponse de la palourde japonaise, Ruditapes philippinarum, exposée à la bactérie Vibrio tapetis: influence de la température et du régime algal, (2015).

[15] C. Le Bris, G. Richard, C. Paillard, C. Lambert, C. Seguineau, O. Gauthier, F. Pernet, F. Guérard, Immune responses of phenoloxidase and superoxide dismutase in the manila clam Venerupis philippinarum challenged with Vibrio tapetis - Part I: Spatio-temporal evolution of enzymes' activities post-infection, Fish \& Shellfish Immunology. 42 (2015) 16-24. doi:10.1016/j.fsi.2014.10.021.

[16] C. Paillard, P. Maes, Brown ring disease in the Manila clam Ruditapes philippinarum: establishment of a classification system, Diseases of Aquatic Organisms. 19 (1994) 137-146.

[17] S. Lindgreen, AdapterRemoval: easy cleaning of next-generation sequencing reads, BMC Research Notes. 5 (2012) 337.

[18] A.M. Bolger, M. Lohse, B. Usadel, Trimmomatic: a flexible trimmer for Illumina sequence data, Bioinformatics. 30 (2014) 2114-2120. doi:10.1093/bioinformatics/btu170.

[19] R. Schmieder, R. Edwards, Quality control and preprocessing of metagenomic datasets, Bioinformatics. 27 (2011) 863-864. doi:10.1093/bioinformatics/btr026.

[20] E. Kopylova, L. Noé, H. Touzet, SortMeRNA: fast and accurate filtering of ribosomal RNAs in metatranscriptomic data, Bioinformatics. 28 (2012) 3211-3217. doi:10.1093/bioinformatics/bts611.

[21] R. Moreira, P. Balseiro, J.V. Planas, B. Fuste, S. Beltran, B. Novoa, A. Figueras, Transcriptomics of in vitro immune-stimulated hemocytes from the Manila clam Ruditapes philippinarum using high-throughput sequencing, PloS One. 7 (2012) e35009.

[22] M.G. Grabherr, B.J. Haas, M. Yassour, J.Z. Levin, D.A. Thompson, I. Amit, X. Adiconis, L. Fan, R. Raychowdhury, Q. Zeng, et al, Full-length transcriptome assembly from RNA-Seq data without a reference genome, Nature Biotechnology. 29 (2011) 644-652. doi:10.1038/nbt.1883.

[23] G.M. Dias, A. Bidault, P. Le Chevalier, G. Choquet, C. Der Sarkissian, L. Orlando, C. Medigue, V. Barbe, S. Mangenot, C.C. Thompson, Vibrio tapetis Displays an Original Type IV Secretion System in Strains Pathogenic for Bivalve Molluscs, Frontiers in Microbiology. 9 (2018) 227.

[24] B. Allam, C. Paillard, M. Auffret, Alterations in hemolymph and extrapallial fluid parameters in the Manila clam, Ruditapes philippinarum, challenged with the pathogen Vibrio tapetis, Journal of Invertebrate Pathology. 76 (2000) 63-69. doi:10.1006/jipa.2000.494.

[25] C. López, M.J. Carballal, C. Azevedo, A. Villalba, Enzyme characterisation of the circulating haemocytes of the carpet shell clam,Ruditapes decussatus(Mollusca:bivalvia), Fish \& Shellfish Immunology. 7 (1997) 595-608. doi:10.1006/fsim.1997.0112.

[26] G. Wang, Z. Zhang, S. Lin, L. Zhang, B. Wang, S. Wang, Y. Wang, A homologue of 
dermatopontin from Haliotis diversicolor and its response to pathogenic infection, Aquaculture Research. 46 (2015) 1537-1549. doi:10.1111/are.12305.

[27] B. Allam, E. Pales Espinosa, A. Tanguy, F. Jeffroy, C. Le Bris, C. Paillard, Transcriptional changes in Manila clam (Ruditapes philippinarum) in response to Brown Ring Disease, Fish \& Shellfish Immunology. 41 (2014) 2-11. doi:10.1016/j.fsi.2014.05.022.

[28] L. Qiu, S. Jiang, J. Huang, W. Wang, C. Zhu, T. Su, Molecular cloning and mRNA expression of cyclophilin A gene in black tiger shrimp (Penaeus monodon), Fish \& Shellfish Immunology. 26 (2009) 115-121. doi:10.1016/j.fsi.2008.03.022.

[29] L. Chen, C. Mu, J. Zhao, C. Wang, Molecular cloning and characterization of two isoforms of cyclophilin A gene from Venerupis philippinarum, Fish \& Shellfish Immunology. 31 (2011) 1218-1223. doi:10.1016/j.fsi.2011.07.001.

[30] S.S. Bohlson, S.D. O'Conner, H.J. Hulsebus, M.-M. Ho, D.A. Fraser, Complement, C1q, and C1q-Related Molecules Regulate Macrophage Polarization, Frontiers in Immunology. 5 (2014). doi:10.3389/fimmu.2014.00402.

[31] T.W. Du Clos, C. Mold, Pentraxins (CRP, SAP) in the process of complement activation and clearance of apoptotic bodies through Fcy receptors:, Current Opinion in Organ Transplantation. 16 (2011) 15-20. doi:10.1097/MOT.0b013e32834253c7.

[32] W.-C. Song, Crosstalk between Complement and Toll-Like Receptors, Toxicologic Pathology. 40 (2012) 174-182. doi:10.1177/0192623311428478.

[33] P. Parham, C. Janeway, The immune system, Fourth edition, Garland Science, Taylor \& Francis Group, New York, NY, 2015.

[34] R.B. Leite, M. Milan, A. Coppe, S. Bortoluzzi, A. dos Anjos, R. Reinhardt, C. Saavedra, T. Patarnello, M. Cancela, L. Bargelloni, mRNA-Seq and microarray development for the Grooved carpet shell clam, Ruditapes decussatus: a functional approach to unravel host -parasite interaction, BMC Genomics. 14 (2013) 741. doi:10.1186/1471-2164-14-741.

[35] B. Allam, C. Paillard, S.E. Ford, Pathogenicity of Vibrio tapetis, the etiological agent of brown ring disease in clams, Diseases of Aquatic Organisms. 48 (2002) 221-231.

[36] J. Liu, G.-P. Shi, W.-Q. Zhang, G.-R. Zhang, W.-H. Xu, Cathepsin L function in insect moulting: molecular cloning and functional analysis in cotton bollworm, Helicoverpa armigera, Insect Molecular Biology. 15 (2006) 823-834. doi:10.1111/j.1365-2583.2006.00686.x.

[37] D. Niu, K. Jin, L. Wang, B. Feng, J. Li, Molecular characterization and expression analysis of four cathepsin L genes in the razor clam, Sinonovacula constricta, Fish \& Shellfish Immunology. 35 (2013) 581-588. doi:10.1016/j.fsi.2013.06.001.

[38] A. Darmoise, P. Maschmeyer, F. Winau, The Immunological Functions of Saposins, in: Advances in Immunology, Elsevier, 2010: pp. 25-62. doi:10.1016/S0065-2776(10)05002-9.

[39] A. Welin, J. Raffetseder, D. Eklund, O. Stendahl, M. Lerm, Importance of Phagosomal Functionality for Growth Restriction of Mycobacterium tuberculosis in Primary Human Macrophages, Journal of Innate Immunity. 3 (2011) 508-518. doi:10.1159/000325297. 
[40] U. Kishore, C. Gaboriaud, P. Waters, A.K. Shrive, T.J. Greenhough, K.B.M. Reid, R.B. Sim, G.J. Arlaud, C1q and tumor necrosis factor superfamily: modularity and versatility, Trends in Immunology. 25 (2004) 551-561. doi:10.1016/j.it.2004.08.006.

[41] G.R. Vasta, M. Quesenberry, H. Ahmed, N. O'Leary, C-type lectins and galectins mediate innate and adaptive immune functions: their roles in the complement activation pathway, Developmental \& Comparative Immunology. 23 (1999) 401-420. doi:10.1016/S0145305X(99)00020-8.

[42] N.D. Marchenko, A. Zaika, U.M. Moll, Death Signal-induced Localization of p53 Protein to Mitochondria a potential role in apoptotic signaling, J. Biol. Chem. 275 (2000) 16202-16212. doi:10.1074/jbc.275.21.16202.

[43] P. Ponka, C. Beaumont, D.R. Richardson, Function and regulation of transferrin and ferritin., Semin Hematol. 35 (1998) 35-54.

[44] K. Orino, L. Lehman, Y. Tsuji, H. Ayaki, S.V. Torti, F.M. Torti, Ferritin and the response to oxidative stress, Biochemical Journal. 357 (2001) 241-247. doi:10.1042/bj3570241.

[45] X. Zhou, W.-J. Liao, J.-M. Liao, P. Liao, H. Lu, Ribosomal proteins: functions beyond the ribosome, Journal of Molecular Cell Biology. 7 (2015) 92-104. doi:10.1093/jmcb/mjv014.

[46] M. Achard-Joris, P. Gonzalez, V. Marie, M. Baudrimont, J.-P. Bourdineaud, cDNA cloning and gene expression of ribosomal S9 protein gene in the mollusk Corbicula fluminea: a new potential biomarker of metal contamination up-regulated by cadmium and repressed by zinc, Environmental Toxicology and Chemistry. 25 (2006) 527. doi:10.1897/05-211R.1.

[47] B. Mazumder, D. Poddar, A. Basu, R. Kour, V. Verbovetskaya, S. Barik, Extraribosomal L13a Is a Specific Innate Immune Factor for Antiviral Defense, Journal of Virology. 88 (2014) 9100-9110. doi:10.1128/JVI.01129-14.

[48] L. Wang, J. Luo, Q. Nian, Q. Xiao, Z. Yang, L. Liu, Ribosomal protein S14 silencing inhibits growth of acute myeloid leukemia transformed from myelodysplastic syndromes via activating p53, Hematology. 19 (2014) 225-231. doi:10.1179/1607845413Y.0000000127.

[49] H.-X. Zhang, Z.-X. Liu, Y.-P. Sun, J. Zhu, S.-Y. Lu, X.-S. Liu, Q.-H. Huang, Y.-Y. Xie, H.-B. Zhu, S.-Y. Dang, H.-F. Chen, G.-Y. Zheng, Y.-X. Li, Y. Kuang, J. Fei, S.-J. Chen, Z. Chen, Z.-G. Wang, Rig-I regulates NF- B activity through binding to Nf- b1 3'-UTR mRNA, Proceedings of the National Academy of Sciences. 110 (2013) 6459-6464. doi:10.1073/pnas.1304432110.

[50] R.M. Martin, N.B. Chilton, M.W. Lightowlers, R.B. Gasser, Echinococcus granulosus myophilin--relationship with protein homologues containing "calponin-motifs," Int. J. Parasitol. 27 (1997) 1561-1567.

[51] A. Goodman, B.L. Goode, P. Matsudaira, G.R. Fink, The Saccharomyces cerevisiae Calponin/Transgelin Homolog Scp1 Functions with Fimbrin to Regulate Stability and Organization of the Actin Cytoskeleton, Molecular Biology of the Cell. 14 (2003) 2617-2629. doi:10.1091/mbc.e03-01-0028.

[52] T.C. Tran, C. Singleton, T.S. Fraley, J.A. Greenwood, Cysteine-rich protein 1 (CRP1) regulates actin filament bundling, BMC Cell Biology. 6 (2005) 45. doi:10.1186/1471-2121-6-45. 
654

655

656

657

658

659

660

661

662

663

664

665

666

667

668

669

670

671

672

673

674

675

676

677

678

679

680

681

682

683

684

685

[53] H.A. Louis, J.D. Pino, K.L. Schmeichel, P. Pomiès, M.C. Beckerle, Comparison of Three Members of the Cysteine-rich Protein Family Reveals Functional Conservation and Divergent Patterns of Gene Expression, Journal of Biological Chemistry. 272 (1997) 27484-27491. doi:10.1074/jbc.272.43.27484.

[54] A. Ghosh-Roy, B.S. Desai, K. Ray, Dynein Light Chain 1 Regulates Dynamin-mediated FActin Assembly during Sperm Individualization in Drosophila, Molecular Biology of the Cell. 16 (2005) 3107-3116. doi:10.1091/mbc.e05-02-0103.

[55] F. Han, Z. Wang, X. Wang, Characterization of myosin light chain in shrimp hemocytic phagocytosis, Fish \& Shellfish Immunology. 29 (2010) 875-883. doi:10.1016/j.fsi.2010.07.030.

[56] U. Röhrig, G. Gerisch, L. Morozova, M. Schleicher, A. Wegner, Coactosin interferes with the capping of actin filaments, FEBS Letters. 374 (1995) 284-286. doi:10.1016/00145793(95)01130-7.

[57] E. Korenbaum, P. Nordberg, C. Björkegren-Sjögren, C.E. Schutt, U. Lindberg, R. Karlsson, The Role of Profilin in Actin Polymerization and Nucleotide Exchange ${ }^{+}$, Biochemistry. 37 (1998) 9274-9283. doi:10.1021/bi9803675.

[58] H. Lodish, ed., Molecular cell biology, 4. ed., [Nachdr.], Freeman, New York, NY, 2002.

[59] R. Hopmann, K.G. Miller, A Balance of Capping Protein and Profilin Functions Is Required to Regulate Actin Polymerization in Drosophila Bristle, Mol Biol Cell. 14 (2003) 118-128. doi:10.1091/mbc.E02-05-0300.

[60] H.G. Mannherz, E. Hannappel, The $\beta$-thymosins: Intracellular and extracellular activities of a versatile actin binding protein family, Cell Motil. Cytoskeleton. 66 (2009) 839-851. doi:10.1002/cm.20371.

[61] A. Weber, Actin binding proteins that change extent and rate of actin monomer-polymer distribution by different mechanisms, Molecular and Cellular Biochemistry. 190 (1999) 67-74.

[62] M. Hertzog, E.G. Yarmola, D. Didry, M.R. Bubb, M.-F. Carlier, Control of Actin Dynamics by Proteins Made of $\beta$-Thymosin Repeats - The actobindin family, J. Biol. Chem. 277 (2002) 14786-14792. doi:10.1074/jbc.M112064200.

[63] C.A. Moore, N. Beckmann, M. Patricia Morse, Cytoskeletal structure of diseased and normal hemocytes of Mya arenaria, Journal of Invertebrate Pathology. 60 (1992) 141-147. doi:10.1016/0022-2011(92)90087-K. 
686

687

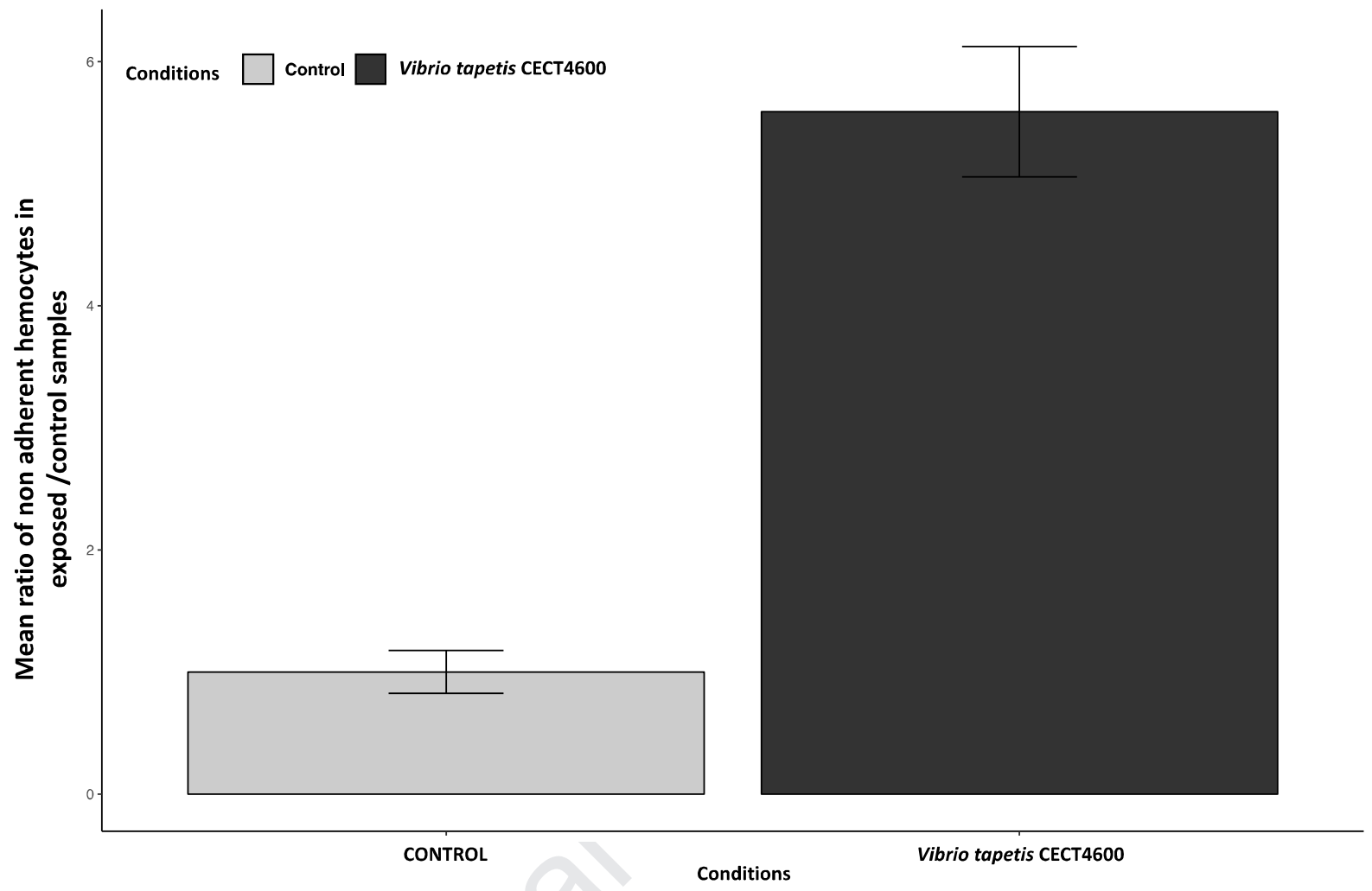

688 Figure 1: Adherence test on hemocytes exposed to Vibrio tapetis CECT4600 (black) or

689 non-exposed (grey) representing the mean ratio of non-adherent hemocytes on exposed 690 / control samples. Error bars = Standard error.

691 


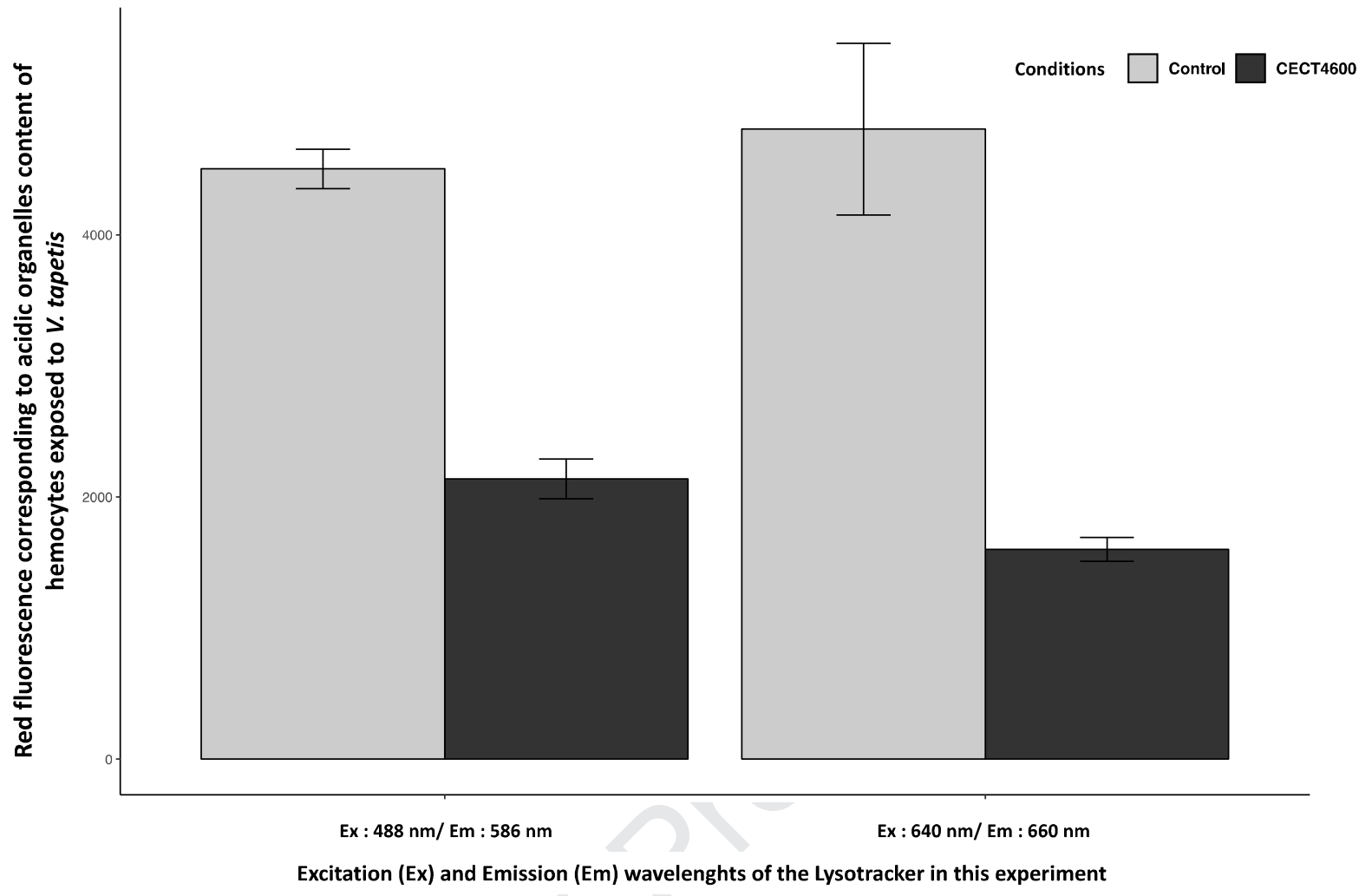

694 Figure 2: Mean red fluorescence of Lysotracker red used as a measure of the amount of 695 acidic organelles in hemocytes, exposed to $V$. tapetis CECT4600 (black) or non696 exposed (grey). Error bars = Standard error. 


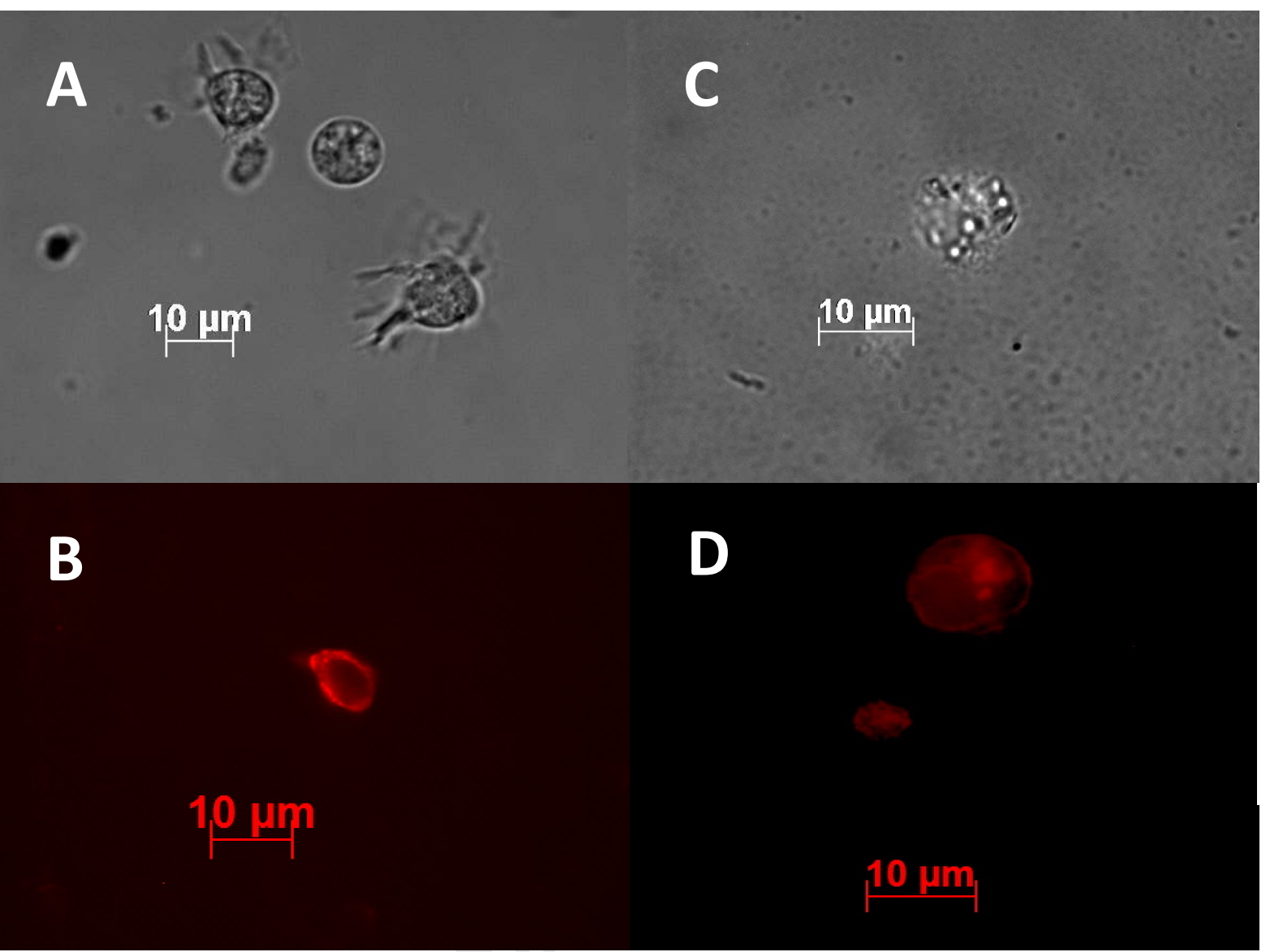

699

700

701 Figure 3: Rhodamine phalloidin staining of F-actin filaments in hemocytes that had been

702 exposed (C, D) or not (A, B) to $V$. tapetis CECT4600. A, C: bright field microscopy

703 observations of control (A) and exposed (C) hemocytes. B, D: epifluorescence

704 observations of control (B) and exposed (D) hemocytes. Wavelengths: excitation, 550

$705 \mathrm{~nm}$; emission, $605 \mathrm{~nm}$. The scale bars $(2 \mathrm{~cm}=10 \mu \mathrm{m})$ correspond to the pictures $\mathrm{A}, \mathrm{B}, \mathrm{C}$ 706 \& D. 
Figure 4A: Immune response of clams to

716 healthy, functional and

717 active hemocytes

718

719

720

721

722

723

724

725

726

Opsonin attachment

Recogni3 on by hemocyte receptors

\section{Foreign}

bacteria

$C 1 q, M B L$

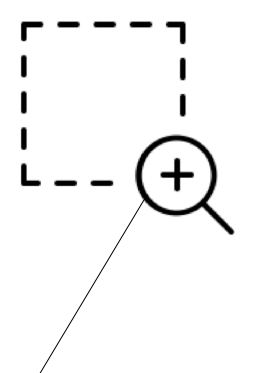

Phagocytosis

Phagosome -

Lysosome fusion

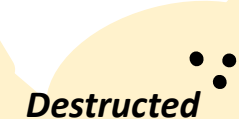

bacteria

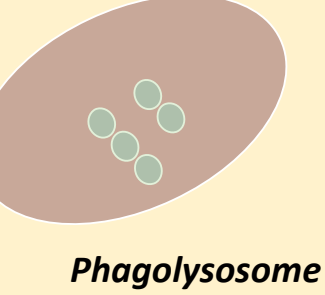

Phagosome

\section{Elongation of pseudopods through F-actin polymerization}

Lysosome

(Cathepsin, Saposin)

Healthy Hemocyte 


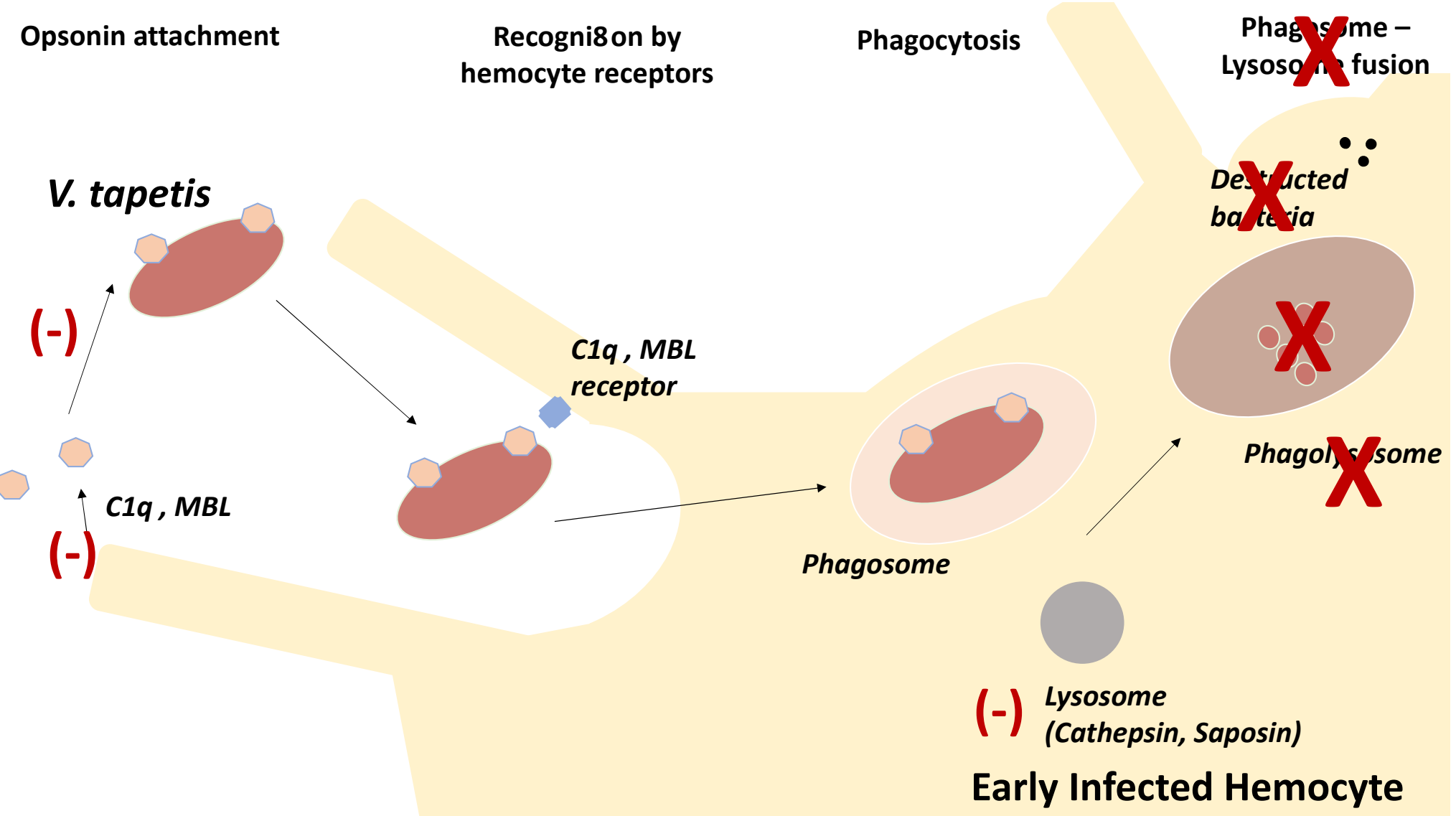

Figure 4B: Immune response of clams to $V$. tapetis on the first steps of infection in early Infected Hemocytes. (-) represent down regulated genes in this study 
767 Figure 4C: Immune response of clams to $V$. tapetis on the 768 late steps of infection in infected, non-functional and, 769 according to our model, resting hemocytes. (-) represent 770 down regulated genes in this study.
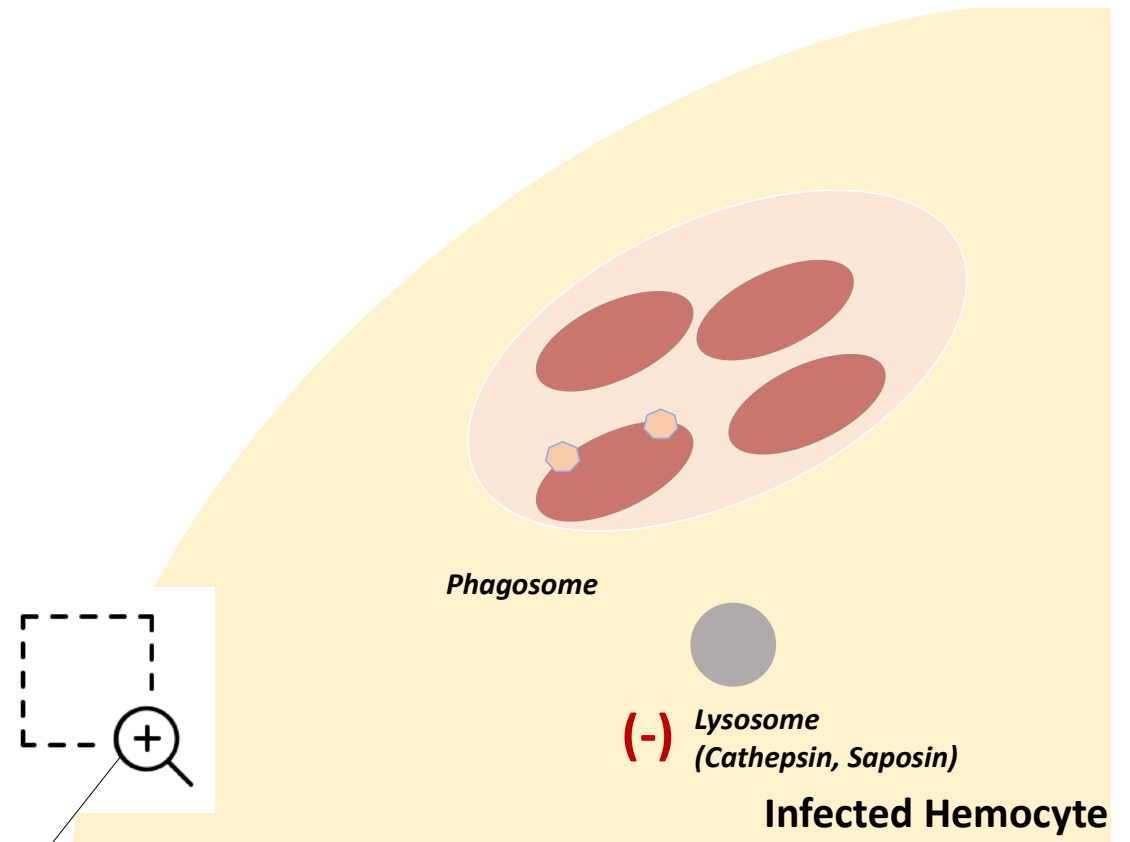

No pseudopods formation : disorganization of F-actin after challenge with $V$. tapetis 


\section{HIGHLIGHTS}

- Brown Ring Disease (BRD) is due to the bacterium Vibrio tapetis, and affects the Manila clam Ruditapes philippinarum

- This study is the first transcriptomic approach based on collection of extrapallial fluids (EPFs) on living animals experimentally infected by $V$. tapetis.

- Transcripts differentially expressed in infected clams are mainly involved in the immune system, translation and in actin cytoskeleton organization

-We showed a downregulation of the immune system related to the complement pathway through $\mathrm{C} 1 \mathrm{q}$ and lectin during infection

-We highlighted a deregulation of transcripts involved in actin organization related to capping proteins

-Physiological validations of immune and actin deregulation were performed

- This study opens new perspectives to explore pathogenicity in the case of BRD. 